\title{
Considerations on the combustion of biofuels in compression ignition engines
}

\author{
Um Min Allah Fazal $^{1}$, Marin Bică ${ }^{* 1}$, Alexandru Gruia ${ }^{1}$, \\ Dragoș Tutunea ${ }^{1}$, Mădălina Călbureanu ${ }^{1}$ \\ ${ }^{1}$ University of Craiova, Faculty of Mechanics, Romania.
}

\begin{abstract}
Biofuels are considered to be attractive alternative fuels due to rising oil prices and the depletion of fossil sources. It is produced by a process of transesterification of vegetable oils and animal fats with an alcohol in the presence of a catalyst. At present, biodiesel and bioethanol are considered solutions, and almost all EU countries have prepared a policy on the production and use of biodiesel in the transport and heating sectors. Biodiesel has certain advantages, such as a higher number of cetan, biodegradability, low sulfur content and aromatic content, and lower carbon monoxide emissions, unburned hydrocarbons and particulate matter. One of the main issues related to biodiesel and biodiesel blends is the high viscosity of the fuel. Among the biodiesel properties, density, viscosity and heating value affect engine performance and emission characteristics. The presented paper highlights the differences that occur in comparison to the classical fuels and the performances obtained when using biodiesel.
\end{abstract}

\section{General consideration}

The development of the transports required the improvement of Diesel engines, especially since the steam engines that used the railway transport locomotives did not respond to the needs (tasks and speeds) The emergence of oil, the rapid development of the oil industry, led to the neglect of the use of biodiesel, due to the undeniable qualities the refined fuels and the low price at that time. The increase in oil consumption during World War II has led to the depletion of their production. The idea of using biofuels has become a solution. For engines evolved at that time, the high viscosity of biodiesel did not allow it to be used. In 1937, G. Chavanne, a Belgian, invented transesterification of vegetable oil, a process that enabled the efficient use of these fuels, which proved to be environmentally friendly. In the 1980s, environmental pollution increased, global temperature increased - global warming. Since then, the European Union has become the largest biofuel producer. The first motors were built to work with vegetable oils without being subjected to further processing. Biodiesel has several advantages such as: since is made from animal fats or vegetable oil reduce the dependence of petroleum products, can be used in existing engines with little or

* Corresponding author: Marin Bică, marinbica52@gmail.com 
no modifications, reduce the greenhouse gases by $78 \%$ according to the experts, can be produces in local refineries reducing transportation cost, is safe to handle (flash point over $150^{\circ} \mathrm{C}$ comparative with $52{ }^{\circ} \mathrm{C}$ for diesel fuel) and positive economic impact since biodiesel is produced locally. The disadvantages include the variation in biodiesel quality, problems in cold weather, the rising price for raw materials used for biodiesel production, the increase of using fertilizers for biodiesel crops and clogging the fuel filters in the engine. There is an increase in nitrogen oxides and degradation of tropical rainforests replaced by palm plantations [1].

\section{Physical-chemical properties}

The structure of the injection jet from combustion chamber determines the increases of engine performance and reduces pollutant emissions. The geometry of the injector, size and nozzle is selected function of the fuel properties, the combustion chamber architecture and the engine's energy solution. The larger angle of the injection cone decreases the penetration and interference between the jets. Hiroyasu and Arai proposed the relationship for determining the angle of the injection jet cone:

$$
\theta=83.5\left(\frac{1}{d}\right)^{-0.22}\left(\frac{d}{D_{O}}\right)^{0.15}\left(\frac{\rho_{g}}{\rho_{l}}\right)^{0.26}, \text { [degrees] }
$$

d- diameter of the spray jet, [m]

$\mathrm{D}_{0}$ - diameter of the cylinder, $[\mathrm{m}]$

$\rho_{\mathrm{g}}$ - gas density in the combustion chamber, $\left[\mathrm{kg} / \mathrm{m}^{3}\right]$

$\rho_{1}$ - density of spray liquid, $\left[\mathrm{kg} / \mathrm{m}^{3}\right]$

The spraying angle is based on:

- the geometry of the spray jet hole;

- kinematic viscosity of the fuel - affects only the limits of the jet;

- injection pressure - increases the angle of the jet;

- fuel density - decreases the angle of the jet;

- temperature - decreases the angle of the injection jet.

The characteristics of the spraying of biodiesel-diesel mixtures were determined by using an atmospheric pressure spray gun using two types of injectors, figures 1,2 and 3 . The density and viscosity of the fuel are important in determining the spray characteristics. The kinematic density and viscosity of the fuel mixture has an increase as the biodiesel concentration of the mixture increases in the blend. 


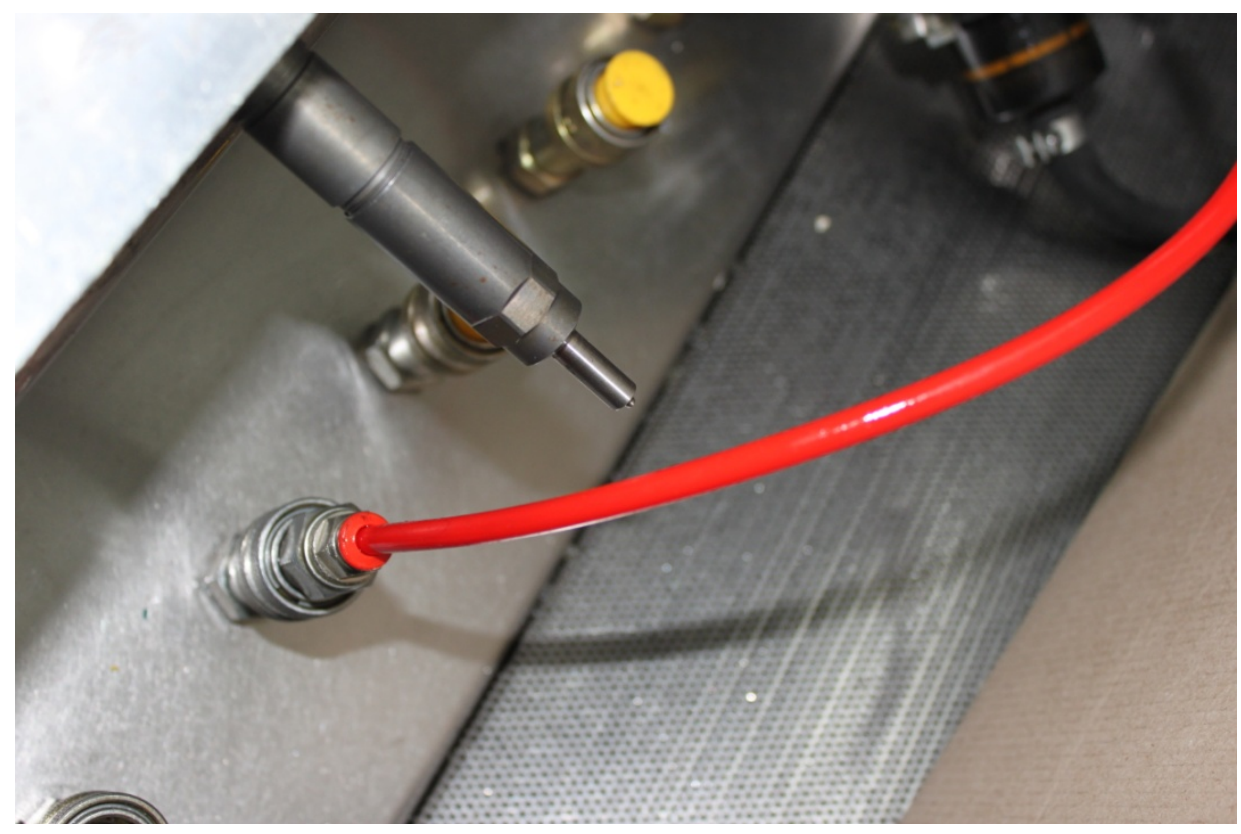

Figure 1. Bosch common rail piezoelectric injector, BMK type engine

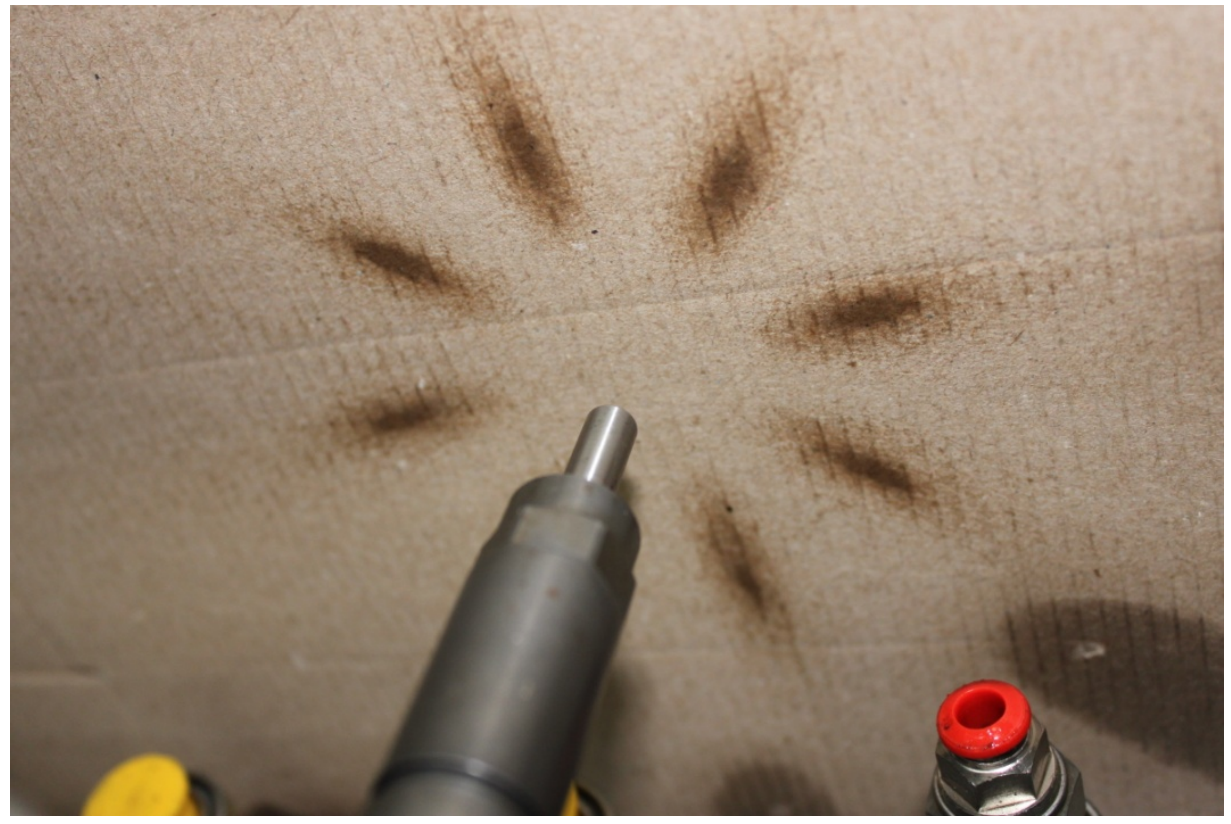

Figure 2. Fuel spraying 


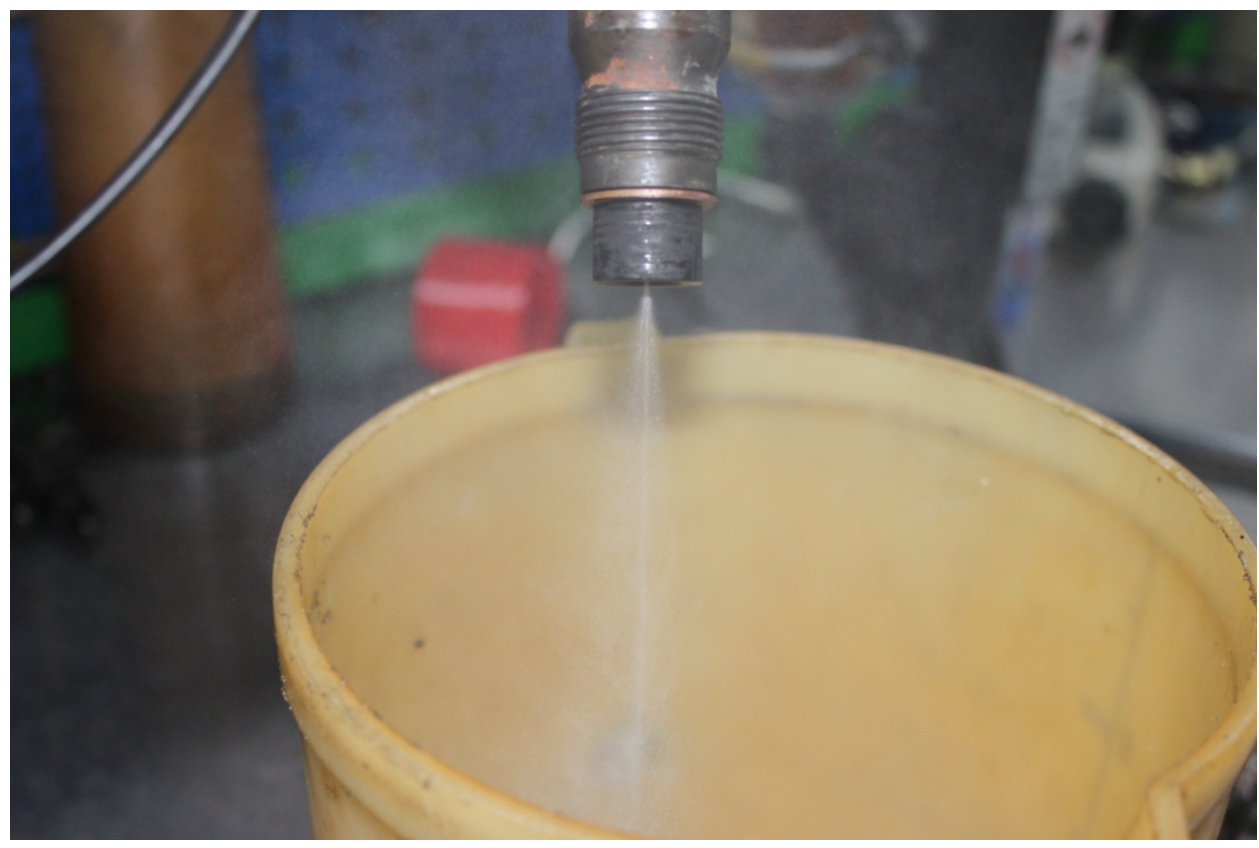

Figure 3. Injector Delphi.Tip VM Motori engine 2,5 1. Spray in the atmosphere

Table 1. Biofuel properties

\begin{tabular}{|l|l|l|l|}
\hline The determined size & Value & Testing method & EN 14214 \\
\hline Density at $15^{\circ} \mathrm{C}, \mathrm{Kg} / \mathrm{m}^{3}$ & 875 & EN ISO 3675 & $860-900$ \\
\hline Refractive index & 1,4562 & ASTM D 1298 & $\geq 1,4900$ \\
\hline Viscosity at $40^{\circ} \mathrm{C}, \mathrm{mm}^{2} / \mathrm{s}$ & 4,719 & EN ISO 3104 & $3,5-5$ \\
\hline Acidity, $\mathrm{mg} \mathrm{KOH} / \mathrm{g}$ & 0,370 & $\leq 0,5$ & PeEN 14104 \\
\hline Iodine index, $\mathrm{gI} / \mathrm{l} / \mathrm{g} \mathrm{g}$ & 128 & PrEN14111 & $<120$ \\
\hline Saponificat index, gKOH/g & 187,4 & AOAC $(1999)$ & $185-190$ \\
\hline Flash point, ${ }^{\circ} \mathrm{C}$ & 178 & ASTM D 6751 & Min 101 \\
\hline Freezing point, ${ }^{\circ} \mathrm{C}$ & -7 & EN 2315 & - \\
\hline Cloud point, ${ }^{\circ} \mathrm{C}$ & -2 & - & - \\
\hline $\begin{array}{l}\text { Stability at } \text { oxidation } \text { at } \\
110^{\circ} \mathrm{C}, \mathrm{h}\end{array}$ & 8 & EN 14112 & Min 6 \\
\hline Distillation, ${ }^{\circ} \mathrm{C}$ & 307 & ASTM D 6751 & Max 360 \\
\hline
\end{tabular}

\section{Influence of parameters determined on biodiesel quality}

\subsection{Density}

In general density is a key parameter that affects the engine operation parameters and pollutant emissions. Researchers define the density as the mass per unit volume of a fluid. In diesel engines the system of injection delivers the biodiesel by volume not by mass, this property influence the quantity of the fuel injected by cycle. Also the air-fuel mixture in the combustion chamber is influenced by the fuel density due to the variation in the energy content. The density of biodiesel is higher than those of petroleum fuel. For all types of 
biodiesel, the tendency to change the density is the same, over time it increases with storage time. This phenomenon happens due to the change in biodiesel structure in the oxidation process. Samples containing hydrocarbons with shorter chains and saturated fatty acids tend to crystallize more quickly. This has as a result the decrease in volume and thus the increase in density. The mass of the sample also increases as a result of insoluble sediment formation, which also leads to increased density.

\subsection{Kinematic viscosity}

It is a parameter that expresses the friction between the interstices of a fluid being a major parameter in assessing the quality of liquid fuels. Viscosity influence the atomization of the fuel when is injected in the combustion chamber due to the formation of large droplets resulting in formation of deposits in the engine. The transesterification process reduce the viscosity of vegetable oil / animal fats which is approximately 10 times higher than petrodiesel fuel to a value closer to that of diesel fuel $[2,3]$. High viscosity and poor cold properties is the main reason why the use of vegetable oil has been abandoned. The majority of biodiesel and diesel standards include biodiesel as a key parameter to be used to monitor biodiesel composition. Researchers reported that viscosity is dependent of the chain length (number of atoms of carbon) and the degree of saturation. Viscosity increases with chain length (number of carbon atoms) and degree of saturation. This also applies to the alcoholic portion because the viscosity of the ethyl ester is slightly higher than that of the methyl ester [2]. Viscosity of fuels is taken into account in engine design specifications, is directly responsible for flow and lubrication properties; the increase in viscosity leads to a tempering of the injector nozzles. Biodiesel with high viscosity leads to the formation of too large droplets that will penetrate the wall opposite the injector. If the surface of the cylinder is cold, the combustion reaction will be interrupted and black smoke will be formed (the intermediate product of combustion consisting of aldehydes and acidic causticodorous acids). Incomplete combustion results in lower engine power.

\subsection{Flash point}

An increased flammability of biodiesel indicates that it has a low probability of accidental ignition. Changing the flash point can be influenced by the residual methanol in the biodiesel production process. The methanol residue may cause degradation of engine elastomers and seals, as well as the corrosion of the aluminum and zinc present in the injectors. The flash point gives indications of the presence of unreacted methyl alcohol in the biodiesel process. It is also important in relation to the legal requirements and safety measures involved in fuel handling and storage and are usually specified in the regulations on fire safety measures [4].

\subsection{Cloud point}

It is the temperature at which the first crystals appear in the mass of biodiesel. They notice visually and under these conditions biodiesel can only be used at a higher temperature. The cloud point variations leads to problems related to the decrease of the flow through the injection pump (decrease of the engine power), the clogging of the filters and the supply pipes. The parameter is an indicator of the temperature at which saturates can flocculate (coagulated as vials), which leads to increased viscosity; at the same time, sets the temperature at which a fuel can no longer be filtered within a specified time limit; shows the injection system blocking potential; shows the destination for use in cold weather or cold season; allows analysis of the need to add additives; can be controlled by mixing raw materials; the parameter also characterizes the determination of the fog point (precipitation of crystals). The cloud point is relative to the degree of saturation and the number of carbon atoms in the fatty acid chain. 
Saturated fat compounds have increased melting points than unsaturated fatty compounds and crystallize in a mixture at superior temperatures than unsaturated compounds. Thus, biodiesel fuels produced by fats or vegetable oils with significant amounts of saturated fatty compounds will have greater cloud points. The increase in the flash point can be improved by the addition of additives [5].

\subsection{Freezing point}

It is the temperature at which biodiesel gels and does not flow. The mixture can no longer be pumped to the engine and it is necessary to heat it. A high value can limit its use in cold climates. An important role in modifying the freezing point is paraffinic substances which, upon cooling, form a network of crystals, thus preventing the movement of the oil. Apart from the presence of paraffin, the freezing point also depends on a number of factors including: the content of resinous and asphaltic substances, the water content of the oils, the preheating temperature, and the cooling temperature of the oils [6].

\subsection{Acidity index}

Indicates the amount of free acids in biodiesel. They come from two sources: from acids used in the production of biodiesel and which have not been completely eliminated and from oxidative degradation. Increased acidity can cause corrosion, deposits in the feed system or clogging of filters due to increased viscosity at the same time may be a symptom of the presence of water in the product.

\section{7 lodine index}

The iodine value is an indicator of stability and a measure of total unsaturation; increased iodine value is closely linked to polymerization to oligomers and leads to damage to the injector; low-value iodine oils are less sensitive to oxidation processes.

\subsection{Distillation temperature}

In the case of unusually low distillation temperatures, these were effectively combined with a low boiling point and flash point indicating high residual amounts of methanol and / or glycerin content. Lower the $10 \%$ distillate temperature value is, easier will be the engine to start in cold climate. The temperature at which it distills $50 \%$ of the volume of biodiesel exerts an influence on the good running of the engine, that is, these average fractions influence the quality of the fuel mixture in the case of a heated engine leading to a stable engine operation and a smooth passage from the running regime empty at the medium speed. The wear of the piston rings, of the bearings, of the cylinders liners is influenced by the heavy fraction characterized by the temperature at which it distills $90 \%$ of the fuel, since the heavy fractions in a high percentage remain unvaporized and dissolve the oil thus creating a possibility of dry friction between the engine organs. Also, heavy fractions in liquid form are not in contact with air and do not burns completely in the combustion chamber, creating calamines that produce engine wear [7].

\subsection{Saponification index}

This property indicates the quantity of saponifiable units (for example acyl groups) per unit of biodiesel weight. A high level shows a higher quantity of low molecular weight fatty acids in the vegetable oil or vice versa. The saponification index is used to measure the average molecular weight of biodiesel and is indicated in milligrams of potassium hydroxide (mg KOH / biodiesel). The saponification process is a chemical reaction in which is produced metal salt or soap. In this reaction the hydroxide ion, -OH reacts with the 
methyl esters, free fatty acid or triglycerides. If the water is present in biodiesel this reaction cannot be removed. There is always a little water and there is always a soap that is formed when biodiesel is produced $[8,10]$. However is a possibility when are used solid (heterogenous) catalysts which do not give the free metal ions necessary to form soap. This solution which involves the biodiesel production and glycerin free can be used at large scale eliminating the quality problems of biodiesel. In fact, many of these heterogeneous catalysts present themselves problems by the fact that eliminate metal ions in the liquid and thus requiring the cleaning of the reaction products. The soap residue should be removed from the biodiesel after the reaction, and this can be done either by washing with water using a liquid-mixed solid adsorbent or by passing the liquid through an ion exchange resin bed.

\subsection{Refractive index}

It changes when the temperature of the biodiesel is near the point of disruption being a significant parameter for assessing its state. An increased refractive index indicates the presence of unsaturated substances.

\subsection{Oxidation stability}

It is expressed as the ability of a fuel to resist chemically to the changes occurring over time over the storage period. It is a major factor in the commercialization of large scale of biodiesel. One of the major problems which restrict the biodiesel usage in internal combustion engines is its poor oxidative stability. Biodiesel can be affected during long period of storage by the oxidation process in contact with air and in contact with water by hydrolytic degradation. Biodiesel may be affected by oxidation during storage (in contact with air) and hydrolytic degradation (in contact with water). These two processes can be referred as the biodiesel stability at oxidation and hydrolytic. The stability of biodiesel can be characterized by two major aspects: long period of storage (stability) or stability in condition of pressure and temperature when biodiesel is used in the engine fueling system. For the renewable fuels the oxidation stability is very important and biodiesel producers have to find methods to improve the biodiesel quality by using additives or extend the guarantee by more than six mounts. By analyzing biodiesel composition which is composed by fatty acids of different carbon chain especially polyunsaturated the tendency to oxidize is very high. After the oxidation process begin the hydro peroxides composed by hydrogen atom and two oxygen atoms are added to the chain of fatty acids. Also the oxidation process can be started by the materials used for recipients used to storage biodiesel or even light. The chemical reaction produces hydroperoxides which can react to produce aldehydes ketones and short chain fatty acids. Hydroperoxides in turn can polymerize to form large molecules. Thus, the process of oxidation increases the viscosity of biodiesel. In addition, oxidation increases the acid value of the fuel, the color can change from yellow to brown with the appearance of a paint smell and solid deposits appears in the engine fuel system (pipes and filters) [11,12]. For example, calculations were made for burning diesel and biodiesel. Results are shown in tables and graphics.

Table 2. Elementary composition of diesel fuel, colza biodiesel and FAME (Biodiesel)

\begin{tabular}{|c|c|c|c|}
\hline Elements & Colza biodiesel & Diesel & Biodiesel \\
\hline Carbon (\%) & 76 & 86.8 & 76.2 \\
\hline Hydrogen (\%) & 14.5 & 12.6 & 12.6 \\
\hline Oxygen (\%) & 6.3 & 0 & 11.2 \\
\hline Azote (\%) & 3.2 & 0 & 0 \\
\hline
\end{tabular}

*Laboratory tests were performed with colza biodiesel 
Table 3. Values $\mathrm{V}_{\text {air }}, \mathrm{V}_{\mathrm{i}}$ and $\mathrm{V}_{\mathrm{O} 2}$ for full burning of colza biodiesel

\begin{tabular}{|c|c|c|c|}
\hline$\lambda$ & $\mathbf{V}_{\text {air }}[\mathbf{k m o l a i r} / \mathbf{k g . c o m b}]$ & $\mathbf{V}_{\mathbf{i}}[\mathbf{k m o l} / \mathbf{k g . c o m b}]$ & $\mathbf{V}_{\mathbf{O} 2}[\mathbf{k m o l} / \mathbf{k g . c o m b}]$ \\
\hline 1.2 & 12.489 & 12.495 & 0.437 \\
\hline 1.4 & 14.518 & 14.524 & 0.874 \\
\hline 1.6 & 16.664 & 16.67 & 1.31 \\
\hline 1.8 & 18.74 & 18.7468 & 1.75 \\
\hline 2 & 20.83 & 20.8368 & 2.18 \\
\hline
\end{tabular}

Table 4. Values for $V_{\mathrm{CO}_{2}}, V_{\mathrm{H}_{2} \mathrm{O}}, V_{\mathrm{N}_{2}}$ și $V_{g}$ at the full burning of colza biodiesel

\begin{tabular}{|c|c|c|c|c|}
\hline$\lambda$ & $V_{\mathrm{CO}_{2}}$ & $V_{\mathrm{H}_{2} \mathrm{O}}$ & $V_{\mathrm{N}_{2}}$ & $V_{g}$ \\
\hline 1.2 & 1.42 & 1.62 & 9.987 & 15.11 \\
\hline 1.4 & 1.42 & 1.62 & 11.63 & 18.836 \\
\hline 1.6 & 1.42 & 1.62 & 13.16 & 22.449 \\
\hline 1.8 & 1.42 & 1.62 & 14.924 & 26.296 \\
\hline 2 & 1.42 & 1.62 & 16.569 & 30.024 \\
\hline
\end{tabular}

Table 5. Values $\mathrm{V}_{\text {air }}, \mathrm{V}_{\mathrm{i}}$ și $\mathrm{V}_{\mathrm{O} 2}$ for complete burning of Diesel

\begin{tabular}{|c|c|c|c|}
\hline$\lambda$ & $\mathbf{V}_{\text {air }}[\mathbf{k m o l a i r} / \mathbf{k g . c o m b}]$ & $\mathbf{V}_{\mathbf{i}}[\mathbf{k m o l} / \mathbf{k g . c o m b}]$ & $\mathbf{V}_{\mathbf{O} 2}[\mathbf{k m o l} / \mathbf{k g . c o m b}]$ \\
\hline 1.2 & 13.296 & 13.30 & 0.465 \\
\hline 1.4 & 15.512 & 15.517 & 0.93 \\
\hline 1.6 & 17.728 & 17.733 & 1.396 \\
\hline 1.8 & 19.944 & 19.95 & 1.86 \\
\hline 2 & 22.16 & 22.165 & 2.326 \\
\hline
\end{tabular}

Table 6. Values $V_{\mathrm{CO}_{2}}, V_{\mathrm{H}_{2} \mathrm{O}}, V_{\mathrm{N}_{2}}$ și $V_{\mathrm{g}}$ for complete burning of Diesel

\begin{tabular}{|c|c|c|c|c|}
\hline$\lambda$ & $\mathrm{V}_{\mathrm{CO} 2}$ & $\mathrm{~V}_{\mathrm{H} 2 \mathrm{O}}$ & $\mathrm{V}_{\mathrm{N} 2}$ & $\mathrm{~V}_{\mathrm{g}}$ \\
\hline 1.2 & 1.62 & 1.41 & 10.5 & 15.746 \\
\hline 1.4 & 1.62 & 1.41 & 12.25 & 19.702 \\
\hline 1.6 & 1.62 & 1.41 & 14.005 & 23.673 \\
\hline 1.8 & 1.62 & 1.41 & 15.75 & 27.634 \\
\hline 2 & 1.62 & 1.41 & 17.506 & 31.606 \\
\hline
\end{tabular}

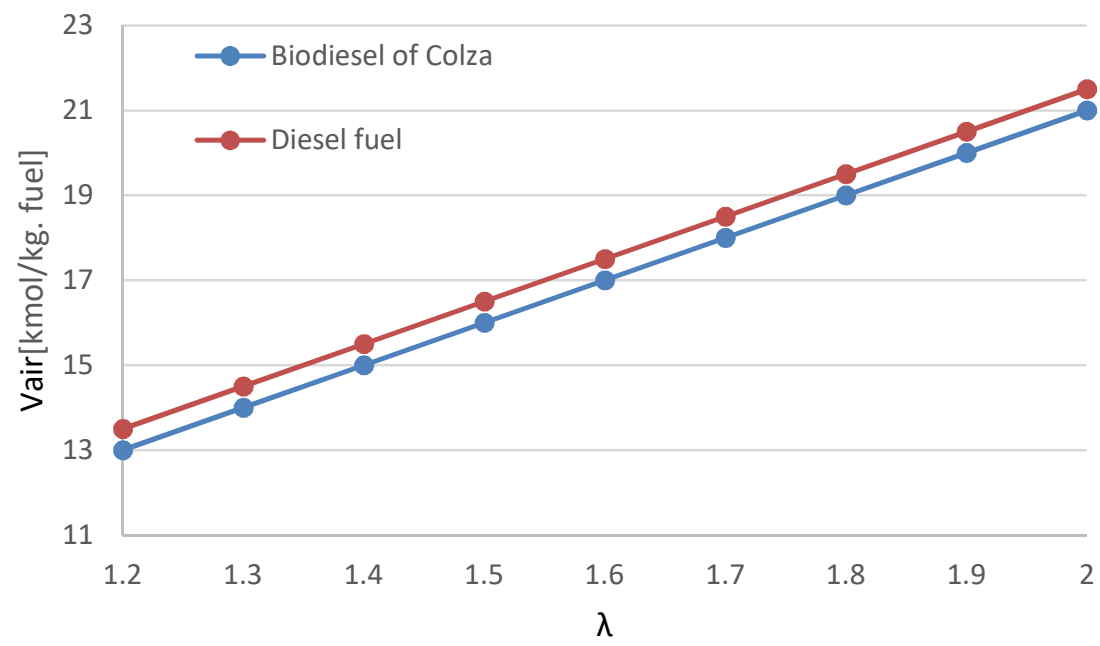

Figure 4. The air required for burning $\left(\frac{\mathrm{m}_{\mathrm{N}}^{3}}{\mathrm{~kg} \cdot \mathrm{comb}}\right)$ 


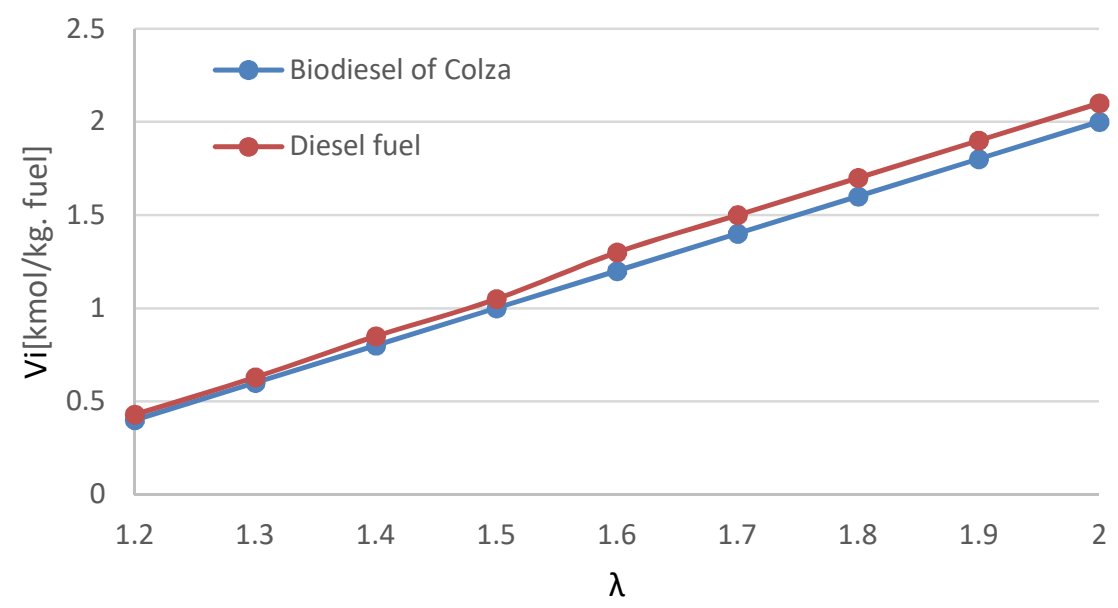

Figure 6. Comparative chart between the excess air $\lambda$ and the number of kilograms of the substance in the reaction

\section{Conclusions}

Based on the experimental results the biodiesel spray has a narrower angle and the penetration is larger than diesel fuel. The biodiesel properties that affect the injection of fuel are fuel vaporization, higher injection pressure and worse atomization. The atomization of biodiesel is the consequence of higher values of surface tension and viscosity comparative with diesel fuel. The results are in accordance with similar rapports from various authors $[6,9,12,14]$.Calculation of combustion indicates that less air is required for biodiesel due to higher content of oxygen.

\section{References}

[1] Aronsson, U. (2011): Processes in optical diesel engines, Doctoral Thesis, Lund University. Sweden.

[2]Information

on http://www.combustiontechnology.co.za/training/incomplete_combustion.htm Accessed on $\underline{31 / 01 / 2016}$

[3] Bennett, S. (2014): Modern diesel technology: Diesel engines, Cengage Learning, Second edition, Stanford, USA.

[4] Baumgarten, C. (2006): Mixture formation in internal combustion engines, Springer. Hannover, Germany.

[5] Weber, J. (2008): Optimization methods for the mixture formation and combustion process in diesel engines, Cuvillier Verlag. Gottingen, Germany

[6] Hiroyasu, H. Arai, M. (1990): Structure of fuel sprays in diesel engines, SAE Technical Paper. ID 900475

[7] Neerinckx, M. Polfliet, T. (2015): Experimental comparison of evaporating diesel sprays from different nozzle geometries, Mater Thesis. Ghent University, Belgium. 
[8] Martinez-Martinez, S. Sanchez, F. Bermudez, V. Riesco-Avila, J. M. (2010): Liquid sprays characteristics in diesel engines, Fuel injection, InTech, Daniela Siano (Ed.), China.

[9] Agarwal, A. K.Som, S. Shukla, P. C. Goyal, H. Longman, D. (2015): In-nozzle flow and spray characteristics for mineral diesel, Karanja and Jatropha biodiesels, Applied energy. Vol. 156, pp. 138-148.

[10] Som, S.Longman, D. E. Ramirez, A. I. A, Aggarwal, S. K. (2010): A comparison of injector flow and spray characteristics of biodiesel with petrodiesel, Fuel. 89, pp. 40144024.

[11] Flynn, P. F. Durrett, R. P. Hunter, G. L. Loye, A. O. Akinyemi, O. C. Dec, J. E. Westbrook, C. K. (1999): Diesel Combustion: An integrated view combining laser diagnostics, chemical kinetics and empirical validation, SAE Technical Papers, UCRL-JC133512.

[12] Agarwal, A. K. Agarwal, A. Singh, A. P. (2015): Time resolved in-situ biodiesel combustion visualization using engine endoscopy, Measurement. 69, 236-249

[13] Tutunea, D. (2013): Thermal investigation of biodiesel blends derived from rapeseed oil, Journal of Thermal Analysis and Calorimetry. 111, pp. 869-875.

[14] Hoekman, S. K.Broch, A. Robbins, C. Ceniceros, E. Natarajan, M. (2012): Review of biodiesel composition properties. 